\title{
SIMULTANEOUS QUANTITATION OF MOXIFLOXACIN AND STATINS INAPI BY RP-HPLC
}

\author{
FATIMA QAMAR ${ }^{l}$, SAFILA NAVEED ${ }^{1 *}$, AISHA SANA ${ }^{1}$, RAFIA USMAN KHAN $^{2}$, M. AZAM ${ }^{3}$ AND HALIMA SADIA $^{1}$ \\ ${ }^{1}$ Faculty of Pharmacy, Jinnah University for Women, Karachi, Pakistan. \\ ${ }^{2}$ Department of Chemistry, NED University of Engineering and Technology Karachi, Pakistan. \\ ${ }^{3}$ Faculty of Pharmacy, Hamdard University, Karachi, Pakistan.
}

\begin{abstract}
Moxifloxacin belongs to broad spectrum flouroquinolone class and having antimicrobial activity. A rapid, cheap, reliable and accurate method has been developed and validated for the simultaneous analysis of Moxifloxacin with statin in active and in dosage formulation. Chromatographic separation was carried out using Purospher star C18 $(5 \mu \mathrm{m}, 25 \times 0.46 \mathrm{~cm})$ column at room temperature $\left(25 \pm 2{ }^{\circ} \mathrm{C}\right)$ with flow rate of $1 \mathrm{ml} / \mathrm{min}$, detector was set at $250 \mathrm{~nm}$ and mobile Phase was 95:5 v/v methanol: water. The correlation coefficient of both drugs was found to be $>0.990$ and 0.999 . Small sample is taken for limit of quantification.
\end{abstract}

Keywords: Moxifloxacin, statins, HPLC, method validation.

\section{INTRODUCTION}

Moxifloxacin chemically known as 1-cyclopropyl-7-(2, 8-diazabicyclo(4.3.0) non-8-yl)-6-fluoro-8-methoxy-1,4-dihydro-4-oxo-3-quinolinecarboxylic acid. Its molecular formula is $\mathrm{C}_{21} \mathrm{H}_{24} \mathrm{FN}_{3} \mathrm{O}_{4}$ belongs to fourth generation fluoroquinolones and inducted for the treatment of community acquired pneumonia (CAP), complicated intra-abdominal infection, acute exacerbation of chronic bronchitis (AECB), acute bacterial sinusitis, plaque and complicated and uncomplicated skin infections.

Moxifloxacin, being a part of quinolone derivatives acts by inhibiting two enzymes i.e., DNA gyrase and topoisomerase VI which are essential for the DNA synthesis. It is a broad spectrum antibiotic which also proven to be active against penicillin resistant Streptococcus pneumoniae. Moxifloxacin is available in both oral and intravenous formulation administer as once a daily dose of $400 \mathrm{mg}^{1-3}$.

Hypercholesterolemia is marked by excessive serum cholesterol levels which is the primary cause of several health implications including cardiovascular disorders. Statins are well-known lipid lowering agent capable to inference in the mevalonate pathway and interact with HMG-CoA reductase to inhibit the cholesterol synthesis. As mevalonate is not solely the precursor of cholesterol, inhibition of HMG-CoA reductase prevent the formation of other bioactive compounds results in a pleiotropic effect.

Apart from lipid lowering effect, they also impart significant effect on the atherosclerosis, vascular tissues, glucose metabolism, bones and kidney. Moreover, statin reportedly reduced the chances of cardiac events, nephropathy and diabetes. They have a positive effect on nitric oxide production (both vascular and glomerular), reduce vascular inflammation and also thought to increase insulin sensitivity ${ }^{4-9}$.

Atorvastatin $\left(\mathrm{C}_{33} \mathrm{H}_{35} \mathrm{FN}_{2} \mathrm{O}_{5}\right)$ and Simvastatin $\left(\mathrm{C}_{25} \mathrm{H}_{38} \mathrm{O}_{5}\right)$ as a members of HMG-CoA reductase inhibitors are often prescribed in various clinical settings for their anti-lipidemic effect. Simvastatin and Atorvastatin introduce in 1988 and 1997 respectively to decrease the serum level of bad cholesterol (LDL) followed by reduction in VLDL, triglycerides and apolipoprotein while both of them modestly increase serum levels of (HDL) i.e., good cholesterol ${ }^{10-11}$. Although it has been reported that ciprofloxacin (a membrane of fluoroquinolone family) has drug-drug interactions with statin and supposed to cause rhabdomyolysis but moxifloxacin is declared safe from such interactions ${ }^{12-14}$.

Numerous chromatographic methods have been reported in the literature for the determination of Moxifloxacin ${ }^{15-17}$, simvastatin ${ }^{18-19}$ and atorvastatin ${ }^{20-21}$ alone or concurrently with other drugs but no method is reported for the simultaneous determination of the above mentioned drugs using RP-HPLC. The objective of this study was to develop an accurate, sensitive and reproducible method for Reverse Phase-HPLC

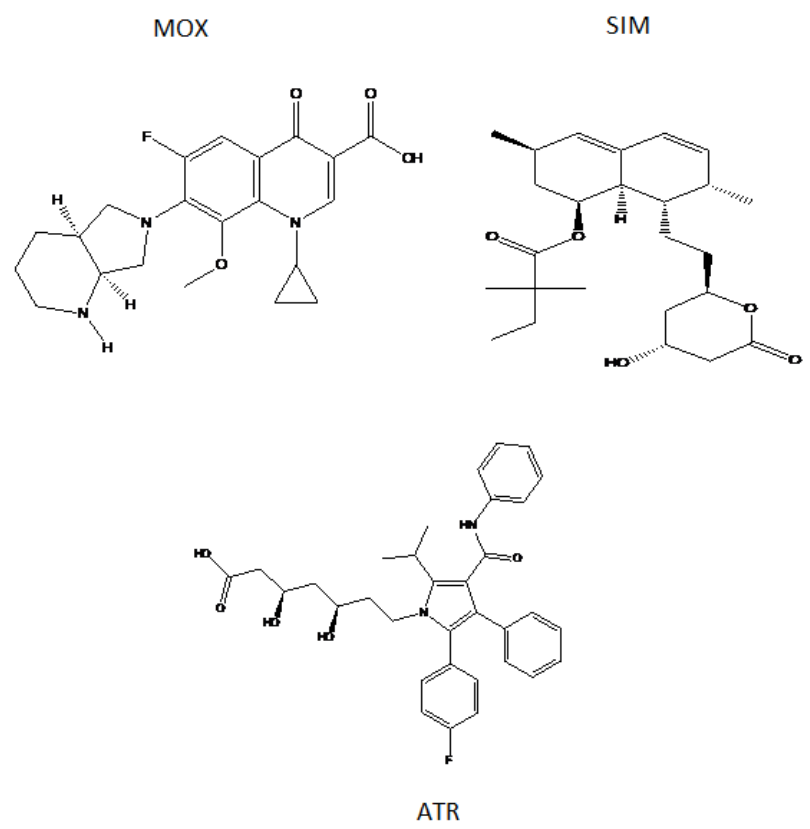

Figure 1. Structure of drugs

Table 1. Concentration Ranges

\begin{tabular}{|c|c|c|c|}
\hline DRUG & $\begin{array}{c}\text { WAVELENGTH } \\
(\mathbf{~ n m})\end{array}$ & $\begin{array}{c}\text { CONC. RANGE } \\
\boldsymbol{\mu g} \text { per ml (UV) }\end{array}$ & $\begin{array}{c}\text { CONC. RANGE } \\
\boldsymbol{\mu g} \text { per ml (HPLC) }\end{array}$ \\
\hline Moxifloxacin & 294 & $1.5625-25$ & $0.39-50$ \\
\hline Atorvastatin & 238 & $1.5625-25$ & $0.39-50$ \\
\hline Simvastatin & 244 & $1.5625-25$ & $0.39-50$ \\
\hline
\end{tabular}

\section{MATERIAL AND METHODS}

\section{Chemicals and Reagents}

Analytical grade chemicals were used to carry out the experiment. Atorvastatin, Simvastatin and Moxifloxacin provided by different pharma from Karachi while orthophosphoric acid and methanol were also obtained from authorized vendors. 


\section{Equipment and Chromatographic conditions}

The system used for the quantification is High Pressure Liquid Chromatography, model Shimadzu-LC-20 AT, with UV-visible detector model SPD-10A (V) v.p., Class LC-20 Version 1:62. The column used for separation is Mediterrean Sea 18 having dimension of $150 \mathrm{~mm} \times 4.6 \mathrm{~mm}$, while internal diameter is $5 \mu \mathrm{m}$ at ambient temperature i.e., $25 \pm 2^{\circ} \mathrm{C}$. Mobile phase is composed of 95:5 ratio of Methanol-water and the $\mathrm{pH}$ of the mobile phase was set in between 3- 4 using the Orthophosphoric acid. The sample injection volume was $10 \mu \mathrm{L}$ at a flow rate of $1 \mathrm{ml} / \mathrm{min}$.

\section{Preparation of Stock Solution}

The stock solution (1000ppm) of each active drug is prepared by reconstituting $100 \mathrm{mg}$ of drug i.e., Moxifloxacin, Atorvastatin or Simvastatin in 100ml of HPLC grade methanol.

\section{Preparation of Working Solution}

From each of the stock solutions, a series of dilutions of each drug was prepared in concentrations of 500ppm, 250ppm, 125ppm, 100ppm, 50ppm, $25 \mathrm{ppm}, 12.5 \mathrm{ppm}, 6.25 \mathrm{ppm}, 3.125 \mathrm{ppm}, 1.562 \mathrm{ppm}, 0.782 \mathrm{ppm}$ and $0.39 \mathrm{ppm}$. These solutions were used for the preparation of working solution by diluting each of these solutions with the mobile phase (Methanol-water 95:5) followed by filtration using 0.45 micron membrane filter. These solutions were then injected in the HPLC column to be analyzed.

\section{Wavelength selection for Detection}

The wavelength under the UV/VIS range i.e., from 200 to $400 \mathrm{~nm}$ was set for each of the solution of moxifloxacin, atorvastatin and simvastatin. Isobestic point of $250 \mathrm{~nm}$ was selected for determination.

\section{Method Validation}

The developed method was validated under the guidelines provided by ICH.

\section{RESULT AND DISCUSSION}

The aim of this study is to establish an accurate, precise and reproducible method with sensitivity, robustness and cost effectiveness to attain simultaneous quantification of Moxifloxacin, Atorvastatin and Simvastatin in a bulk.

\section{Accuracy}

Accuracy of the system was determined by preparing three consecutive concentrations $(100 \pm 20 \%)$ and the resulting Relative Standard Deviation and Recovery (both in percent) was evaluated. \%RSD was found in the range of 1.24 to 1.90 while \% Recovery was obtained in between 95 to 102 which indicate that the method adopted has high level of accuracy as shown in Table 2.

Table 2. Accuracy of Moxifloxacin and statin.

\begin{tabular}{|l|c|c|c|}
\hline \multirow{3}{*}{ Drugs } & Conc. $\boldsymbol{\mu g} \mathbf{~ m l}^{\mathbf{1}}$ & \% RSD & \% Recovery \\
\hline \multirow{4}{*}{ Moxifloxacin } & $80 \%$ & 1.24 & 99.86 \\
\cline { 2 - 4 } & $100 \%$ & 1.40 & 102.81 \\
\cline { 2 - 4 } & $120 \%$ & 1.52 & 100.40 \\
\hline \multirow{3}{*}{ Simvastatin } & $80 \%$ & 1.58 & 99.40 \\
\cline { 2 - 4 } & $100 \%$ & 1.77 & 95.05 \\
\hline \multirow{3}{*}{ Atorvastatin } & $120 \%$ & 1.9 & 101.21 \\
\cline { 2 - 4 } & $100 \%$ & 1.58 & 99.40 \\
\cline { 2 - 4 } & $120 \%$ & 1.77 & 95.05 \\
\hline
\end{tabular}

\section{Precision}

Repeatability and reproducibility in any experiment are prerequisite of a precise method. In the current study, Table 3 describes the inter-day and intraday variations which were evaluated on different concentrations of the active drug solution. It was observed that the \%RSD was within the limit of $2 \%$ and no prominent variation was found among the values of \% Recovery confirming the precision of the developed method.

Table 3. Inter-day and Intra-day precision of Moxifloxacin and statin.

\begin{tabular}{|c|c|c|c|c|c|}
\hline \multirow{2}{*}{ Drugs } & \multirow{2}{*}{\begin{tabular}{|c|} 
Conc. Injected \\
$\mu \mathrm{g} \mathrm{ml}^{-1}$
\end{tabular}} & \multicolumn{2}{|c|}{ Inter-day } & \multicolumn{2}{|c|}{ Intra-day } \\
\hline & & \%RSD & \%Recovery & \%RSD & \%Recovery \\
\hline \multirow{6}{*}{ Moxifloxacin } & 1.5625 & 2.20 & 103.66 & 5.62 & 99.47 \\
\hline & 3.125 & 1.47 & 102.57 & 0.14 & 103.09 \\
\hline & 6.25 & 3.11 & 97.18 & 2.27 & 95.23 \\
\hline & 12.5 & 4 & 99.68 & 4 & 99.68 \\
\hline & 25 & 1.01 & 99.05 & 5.77 & 95.69 \\
\hline & 50 & 1.70 & 102.28 & 1.33 & 100.34 \\
\hline \multirow{6}{*}{ Atorvastatin } & 1.5625 & 3.86 & 102.85 & 1.47 & 100.47 \\
\hline & 3.125 & 0.24 & 95.81 & 7.26 & 98.30 \\
\hline & 6.25 & 0.48 & 99.93 & 2.45 & 98.60 \\
\hline & 12.5 & 0.89 & 103.50 & 2.86 & 101.83 \\
\hline & 25 & 1.57 & 99.64 & 2.58 & 100.47 \\
\hline & 50 & 2.67 & 99.30 & 2.31 & 97.13 \\
\hline \multirow{6}{*}{ Simvastatin } & 1.5625 & 3.86 & 102.85 & 1.47 & 100.47 \\
\hline & 3.125 & 0.24 & 95.81 & 7.26 & 98.30 \\
\hline & 6.25 & 0.48 & 99.93 & 2.45 & 98.60 \\
\hline & 12.5 & 0.89 & 103.50 & 2.86 & 101.83 \\
\hline & 25 & 1.57 & 99.64 & 2.58 & 100.47 \\
\hline & 50 & 2.67 & 99.30 & 2.31 & 97.13 \\
\hline
\end{tabular}

\section{Linearity}

Linearity among the three active drug Moxifloxacin, Atorvastatin and Simvastatin was assessed through the regression equation with $\mathrm{r}^{2} \geq 0.999$. Different concentration of each drug were prepared and the calibration curves were plotted between the peak area and concentration of drug solution to establish the regression equation.

Table 4. Regression Analysis.

\begin{tabular}{|l|c|c|}
\hline Drugs & Regression equations & $\mathbf{r}^{\mathbf{2}}$ \\
\hline Moxifloxacin & $\mathrm{y}=0.0774 \mathrm{x}+0.0932$ & 0.999 \\
\hline Simvastatin & $\mathrm{y}=0.0519 \mathrm{x}+0.0859$ & 0.9997 \\
\hline Atorvastatin & $\mathrm{y}=0.0584 \mathrm{x}+0.1351$ & 0.9944 \\
\hline
\end{tabular}

\section{Selectivity and Specificity}

Clear and sharp peaks were obtained with no interferences of the excipient which indicated the selectivity and specificity of the adopted method.

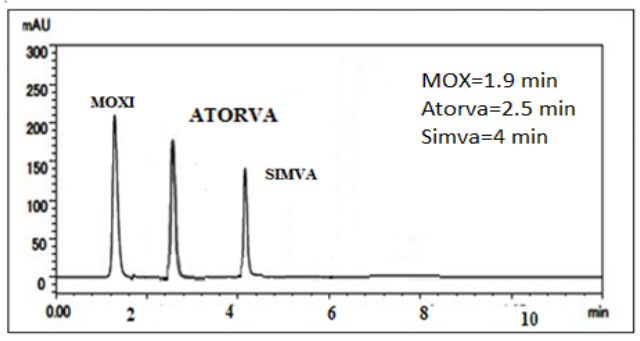

Figure 2. Chromatogram of Moxifloxacin and statins. 


\section{Robustness}

No deviations were observed when the system developed was remain unaffected by the change in the parameters such as $\mathrm{pH}$, flow rate, mobile phase composition and wavelength. The observed data clearly shows the robustness of the developed method Table 5.

Table 5. Method suitability, Robustness of the method.

\begin{tabular}{|c|c|c|c|c|c|}
\hline & Level & $\mathbf{t R}$ & $\mathbf{K}^{\prime}$ & $\mathbf{T}$ & Resolution \\
\hline \multicolumn{6}{|c|}{ A : pH change } \\
\hline 3.0 & -0.2 & 2.5 & 2940.901 & 5.907 & 1.921 \\
\hline 3.2 & $\mathbf{0}$ & 2.9 & 2914.176 & 5.962 & 1.928 \\
\hline 3.4 & 0.2 & 3.1 & 2919.1 & 5.95 & 1.93 \\
\hline \multicolumn{6}{|c|}{ S.D $(n=7)$} \\
\hline \multicolumn{6}{|c|}{$B$ : Flow rate $\mathrm{ml} / \mathrm{min}$} \\
\hline 0.8 & -0.2 & 3.1 & 2935 & 5.9 & 1.89 \\
\hline 1 & $\mathbf{0}$ & 2.9 & 2940.901 & 5.907 & 1.921 \\
\hline 1.2 & 0.2 & 2.6 & 2949.514 & 5.98 & 1.78 \\
\hline \multicolumn{6}{|c|}{ S.D $(n=7)$} \\
\hline \multicolumn{6}{|c|}{$\mathrm{C}: \%$ of methanol in Mobile phase V/V } \\
\hline $90 / 10$ & -5 & 3.0 & 2950 & 5.93 & 1.88 \\
\hline $95 / 5$ & $\mathbf{0}$ & 3.2 & 2949.514 & 5.98 & 1.78 \\
\hline $100 / 0$ & -5 & 3.4 & 2945.321 & 5.98 & 1.75 \\
\hline \multicolumn{6}{|c|}{ S.D $(n=7)$} \\
\hline \multicolumn{6}{|c|}{$D$ : wavelength (nm) } \\
\hline 245 & -5 & 2.8 & 2911 & 5.97 & 3.7 \\
\hline 250 & $\mathbf{0}$ & 2.9 & 2914.2 & 5.92 & 3.2 \\
\hline 255 & 5 & 2.9 & 2942.3 & 5.94 & 3.4 \\
\hline
\end{tabular}

REFERENCES

1. Keating, G.M. \& L.J., Scott (2004) Drugs. 64: 2347-77.

2. Yoshida K., N. Okimoto, M. Kishimoto, H. Fukano, H. Hara, H. Yoneyama, O. Moriya, M. Kawanishi, M. Kimura, T. Matsushima \& Y. Niki (2011) J. Infect. Chemother. 17: 678-85.

3. Fàbrega A., S. Madurga, E. Giralt \& J. Vila (2009) Microbial Biotechnology, 2:40-61.

4. Stancu C \& A. Sima (2001) J. Cell Mol. Med. 5: 378-87.

5. McFarlane S.I., R. Muniyappa, R. Francisco \& J.R. Sowers (2002) J. Clin. Endocrinol. Metab., 87: 1451-58.

6. Tonolo G., M.G. Melis, M. Formato, M.F. Angius, A. Carboni, P. Brizzi, M Ciccarese, G.M. Cherchi \& M. Maioli (2002) Eur. J. Clin. Invest. 30: 980987.

7. Freeman D.J., J. Norrie, N. Sattar, R.D. Neely, S.M. Cobbe, I. Ford, C. Isles, A.R. Lorimer, P.W. Macfarlane, J.H. McKillop, C.J. Packard, J. Shepherd \& A. Gaw (2001) Circulation, 103: 357-362.

8. Meier C.R., R.G. Schlienger, M.E. Kraenzlin, B. Schlegel \& H. Jick (2000) JAMA, 283: 3205-3210.

9. Sirtori C.R. (1990) Pharmacol. Res. 22: 555-563.

10. Ray K.K \& C.P. Cannon (2005) Expert Opin Pharmacother. 6: 915-927.

11. Pedersen T.R. \& J.A. Tobert (2004) Simvastatin: a review. Expert Opin. Pharmacother. 5: 2583-2596.

12. Sawant, R.D. (2009) Can. J. Clin. Pharmacol. 16: 78-9.

13. Čaušević-Ramose, A. \& S. Semiz (2013) Acta Pharmaceut. 63: 277-93.

14. Miao, X.-S. \& C.D. Metcalfe (2003) J. Chromatogr. A 998: 133-41.

15. F. Nur, A. Rahman, M.Z. Sultan, M.G. Uddin, M.A. Rashid, A. Hassan \& M. Ahmed (2013) J. Basic Appl. Sci. 9: 633-638.
16. Sultana N., M. Akhtar, S. Shamim, S. Gul \& M.S. Arayne (2011) Quim. Nova, 34: 683-88.

17. Razzaq S.N., I.U. Khan, I. Mariam \& S.S. Razzaq (2012). Chem. cent. J. 6: 94.

18. Dixit R.P., C.R. Barhate, S.G. Padhye, C.L. Viswanathan \& M.S. Nagarsenker (2010) Indian J Pharm Sci. 72: 204-10.

19. Ochiai H, N. Uchiyama, K. Imagaki, S. Hata \& T. Kamei (1997) J. Chromatogr. B Biomed. Sci. 694: 211-217.

20. Seshachalam U. \& C.B. Kothapally (2008) J. Liq. Chromatogr. Relat. Technol, 31: 714-21.

21. Altuntas, T. G. \& N. Erk (2004) J. Liq. Chromatogr. Relat. Technol, 27: 8393. 